\title{
Nuevos datos acerca de la inscripción califal atribuída al Castillo de Baños de la Encina (Jaén) '
}

\author{
Alberto Canto García * \\ Isabel Rodríguez Casanova ***
}

\begin{abstract}
RESUMEN
El artículo propone una nueva atribución para el epígrafe califal asignado al castillo de Baños de la Encina (Jaén), situando su procedencia en Talavera de la Reina (Toledo), a tenor de la documentación depositada en la Real Academia de la Historia.
\end{abstract}

PALABRAS CLAVE: Al-Andalus, Califato, Fortificaciones, Epigrafía, Baños de la Encina (Jaén), Talavera de la Reina (Toledo).

El motivo del presente artículo es realizar una serie de precisiones acerca de la procedencia de la inscripción islámica adjudicada hasta ahora al castillo de Baños de la Encina (Jaén). Dicha inscripción pertenece a la Real Academia de la Historia y se encuentra depositada desde 1907 en el Museo Arqueológico Nacional.

La primera publicación de este epígrafe corresponde a R. Amador de los Ríos, quien, en 1876, la recoge entre las depositadas en la Real Academia de la Historia y anota su

\begin{abstract}
The paper give us a new attribution for the caliphal inscription from Baños de la Encina's castle in Jaén, with a new origin in Talavera de la Reina (Toledo), thanks to the information in the Real Academia de la Historia.
\end{abstract}

KEY WORDS: Al-Andalus, Caliphate Period, Fortifications, Epigraphy, Baños de la Encina (Jaén), Talavera de la Reina (Toledo).

"dudosa procedencia" (AMADOR DE LOS RÍOS, 1876, p. 149). Se trata de una inscripción de nueve líneas, enmarcada en una triple moldura, alusiva a la fundación de de lo que Amador de los Ríos interpretó como una "vía o camino cuya importancia no es posible quilatar al presente, sin el exacto conocimiento del lugar en que fue descubierto". Esta inscripción vuelve a ser publicada por Ribera (1909), Revilla (1924 y 1932) y ha sido reiteradamente citada por diversos autores que han leído el término bury/torre en lugar de "vía o camino" y asu-

\footnotetext{
*Alberto Canto García: Universidad Autónoma de Madrid, Campus de Cantoblanco, 28049, Madrid.

*** Isabel Rodríguez Casanova: Real Academia de la Historia, C/ León 21, 28014, Madrid.

I Este artículo se inscribe dentro de la acción especial BHA-2002-I0562-E, “Estudio y publicación de las colecciones del Gabinete de Antigüedades de la Real Academia de la Historia y potenciación de su labor científica, concedida por la Dirección General de Investigación de Ciencia y Tecnología; en concreto dentro de la preparación del Catálogo de Epigrafía Andalusí, dirigido por Ma Antonia Martínez Núñez y con la colaboración de Isabel Rodríguez Casanova y Alberto Canto García. Agradecemos al Dr. Sergio Martínez Lillo y a Da Belén Urda, de la UAM, su ayuda y colaboración en el material gráfico y en la documentación relacionada con las murallas de Talavera, así como a D. Rafael Gómez Díaz, Archivero del Excm. Ayuntamiento de Talavera de la Reina, por sus informaciones, y a Da Ángela Franco, conservadora del Museo Arqueológico Nacional de Madrid, por las facilidades prestadas para la consulta de los materiales epigráficos.
} 
miendo todos su procedencia de Baños de la Encina; así Lévi-Provençal (1931), Hernández (1940), Aguirre y Jiménez (1979), Labarta (1990), Zozaya (1995) y Martínez Núñez (200 I, pp. 280281) quien realiza una llamada de advertencia sobre algunas incoherencias cronológicas sobre la fecha de entrada de la inscripción en la Academia) (Fig. I).

Pero la historiografía de esta inscripción merece algunos comentarios. Sorprendentemente, como hemos dicho, en 1909 esta inscripción volvió a ser publicada como inédita por J. RIBERA (1909) y como procedente del Castillo de Baños de la Encina ${ }^{2}$. En su introducción del artículo, el autor menciona que F. Fita le ha señalado la reciente adquisición por parte de la Real Academia de la Historia de una inscripción procedente de Baños de la Encina que estaba inédita. Anota igualmente que de esta inscripción habían dado noticia F. Fita y A. Rodríguez Villa en el Boletín de dicha institución del año 1902 (FITA y RODRÍGUEZ VILLA, 1902, pp. 349 s.). En dicha noticia se menciona, efectivamente, la adquisición por parte de la Real Academia de una laja caliza, hallada en Baños de la Encina "y que procede, a lo que se dice, del antiguo alcázar ó fortaleza de la villa", y que "se halla muy mal tratado el epígrafe por causa de haber estado algunos años tendido en la calle pública y de haber sido lastimado por las pisadas de los transeúntes. A su tiempo daremos cuenta de la lectura y traducción de su contenido" (FITA y RODRÍGUEZ VILLA, 1902, p. 350) ${ }^{3}$. Puesto que Ribera, citando a Fita, señala que se trata de una adquisición reciente, en concreto de 1902, es evidente que no podría tratarse de la inscripción publicada por Amador de los Ríos en 1876 (Sorprende, igualmente, que un arabista de la talla de Ribera desconociera la publicación anterior de Amador de los Ríos).

Paralelamente a la adquisición de esta pieza por la Academia de la Historia, Amador de los Ríos da noticia de su hallazgo en la revista La Ilustración Española y Americana. La descripción y traducción del epígrafe no dejan duda acerca de su identificación. Ambas noticias coinciden, además, en las circunstancias del hallazgo, debido a la mediación del señor Horace Sandars, y que se encontraba formando parte del pavimento, aunque Amador de los Ríos no menciona en ningún momento la posible procedencia del castillo. Por último, el autor avisa de la posibilidad de que este epígrafe pueda viajar a Inglaterra, tal y como habría sucedido con otros hallazgos realizados por el Sr. Sandars, y solicita la intervención de las autoridades para que la lápida se quede en España y sea trasladada al Museo Arqueológico Nacional (AMADOR DE LOS RÍOS, 1902, p. 274).

La documentación depositada en el Archivo de la Real Academia de la Historia, perteneciente a la Comisión de Antigüedades de la provincia de Jaén, permite confirmar la llegada de la pieza a la colección, así como su identificación (números de expediente CAJ/9/7958/26 y 27). Fue donada a la Real Academia a finales de 1902 por D. Ignacio Herreros y Herreros, con la mediación de Horace Sandars, solicitando se hiciese constar el nombre del donante en una futura publicación y se le hiciera llegar una copia de la traducción en el momento en que ésta se llevara a cabo. Junto al expediente de adquisición figura un calco que permite identificarla como una inscripción de cinco líneas, pequeña y en mal estado ${ }^{4}$ (Fig. 2).

\footnotetext{
2 Este artículo es aprobado para su publicación en el Boletín de la Real Academia de la Historia en la Junta de 1909/4/2, en la que se propone, igualmente, a Julián Ribera como académico de número, apoyado, entre otros por Codera y Vives. Textualmente se dice "El Sr. Fita leyó un escrito del Sr. Ribera sobre lápidas arábigas de Tarifa y Baños de Lencina (sic), cuya traducción presenta. Después de hacer algunas indicaciones el Sr. Censor y el Sr. Fita sobre trabajos relativos a inscripciones arábigo-españolas, se acordó que pasase al Boletín".

3 Aunque no deja de ser una percepción subjetiva, es sorprendente que alguien describa un epígrafe de la entidad del publicado por Amador de los Ríos como laja, sustantivo que puede aplicarse con toda propiedad a la inscripción que efectivamente proviene de Baños de la Encina, tal y como puede constatarse en las ilustraciones de este artículo.

4 En la misma línea de confusión de las dos inscripciones, es necesario corregir la inclusión de la fotografía de la inscripción conmemorativa, la publicada en 1876, en el expediente de donación de la segunda inscripción aparecida en Baños de la Encina: véase MAIER et alii, 2000, pp. 274-I75, en especial CAJ/9/7958/26(8).
} 
Así pues, estaríamos hablando de dos inscripciones distintas, ambas depositadas en el Lapidario de la Real Academia: la primera, publicada por Amador de los Ríos en 1876, conmemorativa, de origen y fecha de ingreso inciertos, y una segunda, incorporada a la colección de la Real Academia en 1902, funeraria, publicada en la noticia de Fita y Rodríguez y por Amador de los Ríos nuevamente, que procede, esta sí con seguridad, de Baños de la Encina.

Parece entonces, a nuestro juicio, que es en el momento de la publicación de Ribera cuando se produce la confusión entre las dos inscripciones. El motivo del error pudo haberse originado porque ambas eran propiedad de la Real Academia y se encontraban ya entonces depositadas en el Museo Arqueológico Nacional. Resulta sorprendente que Ribera mencione en su publicación, si bien citando al P. Fita, que las dos inscripciones que estudia en ella, -la atribuida a Baños de la Encina y la del Castillo de Tarifa-, son inéditas. Ambas habían sido publicadas con anterioridad por Amador de los Ríos: la que venimos discutiendo en 1876, y la de Tarifa en 1896 (AMADOR DE LOS RÍOS, 1876, p. 149 y 1896, p. 17-19), aunque esta última era conocida al menos desde el siglo XVIII como testimonia una de las fichas recogidas por el Marqués de Valdeflores que se conserva en el legajo 9/4/28/36.6 de la Real Academia de la Historia (Fig. 3).

La importancia de la primera inscripción, la conmemorativa, la ha hecho objeto de sucesivas revisiones y publicaciones. En todas ellas se ha reproducido la adjudicación del epígrafe al castillo de Baños de la Encina, hasta el punto de que se ha colocado una reproducción de la inscripción sobre su entrada principal. Gracias a la fecha que proporciona, el castillo de Baños de la Encina se viene considerando hasta ahora como uno de los más importantes ejemplos de arquitectura militar califal.
Sin embargo, un repaso detenido por la bibliografía originada por este epígrafe nos revela que las dudas acerca de la adjudicación a Baños de la Encina no eran nuevas. Lévi-Provençal, en su corpus de inscripciones árabes de España, recoge la bibliografía anterior de la inscripción y dice que Amador de los Ríos la conoce a través de una copia (LÉVI-PROVENÇAL, 193I, $n^{\circ}$ 150, p. 134, n. al p.), precisión absolutamente infundada, puesto que Amador publica las inscripciones depositadas en la Real Academia de la Historia, y que, de ningún modo, podría justificar la obvia contradicción que se da en el hecho de que la pieza hubiera aparecido en 1902 pero estuviera publicada desde 1876.

Desde el punto de vista del contenido de la inscripción, son conocidas desde hace tiempo las dudas que planteaba la adjudicación de este epígrafe fundacional al Castillo de Baños de la Encina. La discusión se centra especialmente en el término bury, que aludiría a algún tipo de obra de menor entidad que el castillo al que nos estamos refiriendo; sin embargo es evidente que en las inscripciones de Tarifa y la hasta ahora considerada como de Baños de la Encina se utiliza el término bury aplicado en fortificaciones de relativa envergadura lo que hace suponer que el término debía usarse de forma indistinta, por lo menos en el siglo X (ACIÉN, 1995, pp. 29 y 35; ZOZAYA, 1995 p. 98, ficha 19) 5.

Si estamos en lo cierto en nuestra argumentación y no existe ninguna certeza de que la primera inscripción pertenezca a Baños de la Encina, sería un argumento más a favor de la hipótesis sugerida por Menéndez, Azuar y otros que, en el contexto de un estudio sobre la cronología de un grupo de fortificaciones andalusíes, según criterios constructivos, consideran la obra de época almohade. Tradicionalmente, se ha atribuido una cronología califal a este castillo basándose en el argumento "irrefutable" de la inscripción, por lo que, si

5 Sin embargo en este último, la foto que ilustra no se corresponde con la inscripción en concreto, ya que se trata de una inscripción de Almería, suponemos que por un error de imprenta. 
bien los autores recuerdan la descontextualización del epígrafe, no descartan que pudiera existir una fundación inicial de momento califal (MENÉNDEZ ET AL., 1994, pp. 489 y 50 I). Siguiendo el error perpetuado desde Ribera, y seguido por Lévi-Provençal, consideran que la inscripción aparecida en 1902 es la conmemorativa de la construcción de una torre. En un sentido contrario opina Acién (ACIÉN, 1995, pp. 35) que considera esta fortificación como califal aunque, si estamos en lo cierto en lo que respecta a la inscripción, esta no podría ser utilizada como elemento de datación comparado.

Si descartamos, entonces, la adjudicación de la inscripción a Baños de la Encina, faltaba encontrar de dónde procedía en realidad este epígrafe, respuesta que creemos haber encontrado, de nuevo, en la documentación de la Real Academia de la Historia. Entre las escasas inscripciones originales que son adquiridas por la Academia, ya que la mayoría de los fondos del lapidario los forman copias, calcos o reproducciones, destaca por su importancia la de un epígrafe adquirido en 1768 en Talavera de la Reina (Toledo). La primera noticia de esta inscripción la proporciona J. Hermosilla, quien aporta una copia que le habían remitido, informando, asimismo, de que dicha inscripción se conservaba en ese momento en las Cavas del ayuntamiento de la ciudad. Debido a la importancia de la pieza y la mala calidad de la copia se le pide al Académico informante que consiga una copia exacta para que D. Miguel Casiri pueda interpretarla o, mejor, la lápida misma (Actas de Sesiones de 1768/03/26 y 1768/04/I5).

Las negociaciones con los ediles de Talavera no debieron ser fáciles, a juzgar por lo reflejado en las Actas (1768/04/22) y la Academia parece resignada a renunciar al epígrafe original, encargando el estudio del epígrafe y su ilustración en la lámina correspondiente a partir de las sucesivas copias y dibujos que se le habían ido enviando, hasta que el mismo señor Hermosilla consigue del alcalde talaverano la donación de la inscripción a la Academia: 1768/06/03: "El Sor. Hermosilla informó a la Academia que se hallaba con Carta de Dn Carlos Nava Marino (i), Alcalde Mayor de Talavera de la Reyna, en la que se ofrece de acuerdo con las Capitu- lares del Ayuntam ${ }^{\text {to }}$ de ella el remitir la Lapida Arabe expresada en las Actas anteriores, y consiguiente à la Academia según lo que sobre este particular tenía encargado al Sor. Hermosilla, Acordó que se traiga dcha. lapida".

Ningún dato concreto se aporta en estos documentos acerca del epígrafe, pero prueba indirecta de su importancia es el hecho de la negativa del municipio a desprenderse de la lápida, y del mismo modo indirecto, el costoso envío de la pieza hasta el domicilio del Censor, quien debe recompensar a los mozos porteadores con varios reales para que la suban hasta su casa (que después reclamará a la Academia: Acta de Sesiones de 1768/06/25) nos da idea de que se trata de un objeto de un tamaño y peso considerables.

Las noticias aportadas por la documentación conservada en la Real Academia de la Historia se completan con las recuperadas en los Archivos Municipales de Talavera de la Reina. En concreto en el documento titulado Valor de las rentas de propios y arbitrios, del año 1768 , apartado "Gastos ordinarios y extraordinarios alterables", punto 8, figura el pago de 100 reales por la "Conducción de una piedra a la $R$ ! Academia de la historia. En 15 de Julio, a Dn. Thomas de Mozas Rexor de esta Villa, Cien res von $q^{e}$ suplió y pagó á Berndo. Andres, Mayoral de una Carretria. por la Conducción de una Piedra Lapida, Araves q estava en una de las Murallas de esta Villa y se remitió á Madrid á la Real Academia de la historia" (Fig. 4).

En 1781, el anticuario Sr. Flores, realiza un informe sobre los acuerdos tomados en la Academia en relación con la interpretación de las monedas e inscripciones árabes, donde se menciona de nuevo esta pieza dentro de la relación del año 1768: "En 22 del mismo mes de Abril se acordó que Gil abriese en lámina la Inscripcion Arabe hallada en Talavera, traducida é ilustrada por el Sr. Casiri, que es la misma que posteriormente se trajo original de aquella Villa, y posee la Academia" (GN I78I-I). Suponemos que una lámina de esta inscripción debió formar parte de la colección de 54 láminas de inscripciones y monedas que se grabaron y que fueron entregadas a la Academia en 1778, tra- 
bajo realizado bajo la dirección de Casiri (Memorias de la Real Academia de la Historia, 1796, tomo I, p. $X \mathrm{LIX)}$.

Afortunadamente, una copia de las láminas impresas por Gil para la Academia se ha conservado en el Archivo de la Universidad de Sevilla, dentro del legado de Antonio Delgado, información que nos ha proporcionado $D^{a}$ Fátima Martín Escudero ${ }^{6}$. La lámina 48 presenta un dibujo de la inscripción de la que venimos hablando con el encabezamiento "Ynscripcion Cufica de Talavera de la Reyna" y debajo la transcripción al árabe con el encabezamiento "La misma en letra corriente" (fig. 5). La existencia de este dibujo es la prueba definitiva de la atribución del epígrafe a Talavera de la Reina y no a Baños de la Encina.

Una última muestra del aprecio que la Academia tenía por esta pieza, queda constatado en el siguiente hecho: El 18 de febrero de 1785 , la Infanta $D^{a}$ Carlota se dispone a visitar la Academia y, a tal fin, la Institución se dispone a mostrarle una selección de sus piezas más destacadas. En el apartado dedicado a las inscripciones árabes se seleccionan tres piezas entre las que están una reproducción de la lápida funeraria del príncipe Yusuf que acababa de ser hallada en la iglesia de Santa María de Betanzos, y "la inscripción que se traxo de Talavera".

Desde el punto de vista arqueológico, la posibilidad de que la inscripción proceda efectivamente de Talavera de la Reina, tendría pocos inconvenientes. El recinto murario de la ciudad es considerado unánimemente de época califal, cronología perfectamente acorde con la fecha proporcionada por nuestro epígrafe. Pero además, en una de las torres de la muralla, se conserva un lecho o cama, que, con toda probabilidad, serviría para situar una inscripción relacionada con la construcción (MARTíNEZ LILLO, 1998, pp. 6I, s.) (Fig. 6). Las medidas de ese rebaje en el muro, $66 \times 106 \mathrm{~cm}$, coinciden perfec- tamente con las medidas del epígrafe que estamos estudiando: $61 \times 85,5 \mathrm{~cm}$. ${ }^{7}$. El término bury, cuya aplicación al castillo de Baños de la Encina, resultaba un tanto problemática, como se ha visto anteriormente, es perfectamente aplicable a esta construcción.

Es verdad que existe un cierto desfase cronológico si nos atenemos a los datos relativos a la fundación de Talavera en el año 325H./9367 d.C., en época de Abd al-Rahman III (MARTÍNEZ LILLO, 1998, p. 6I, n. 57), mientras que el epígrafe del que hablamos está fechado en época de Al-Hakam II, su sucesor, del año 357H./967-8 d.C., pero también es cierto que esto no invalida el que se pudiera haber realizado cualquier obra de mejora o refuerzo en el que se situara la citada inscripción.

\section{BIBLIOGRAFÍA}

ACIÉN ALMANSA, Manuel, (1995): "La fortificación en al-Andalus", en La Arquitectura del Islam Occidental, R. LÓPEZ GUZMÁN (coord.), pp. 29-42.

AGUIRRE SÁDABA, F. Javier; JIMÉNEZ MATA, Mª del Carmen, (1979): Introducción al Jaén islámico (estudio Geográfico-Histórico), Jaén.

AMADOR DE LOS RÍOS, Rodrigo, (1876): “Lápidas arábigas existentes en el Museo Arqueológico Nacional y en la Real Academia de la Historia", Museo Español de Antigüedades. Tomo VII. Madrid, pp. I2I-I56.

AMADOR DE LOS RÍOS, Rodrigo, ( 1896 ): "Lápida conmemorativa del castillo de Tarifa", Boletín de la Sociedad Española de Excursiones, tomo III, pp. 17-19.

AMADOR DE LOS RÍOS, Rodrigo, (1902): "Monumentos funerarios de los musulmanes hallados recientemente en Murcia y en Jaén", La llustración Española y americana: museo universal: periódico de ciencias, artes, literatura, industria y conocimientos útiles, vol. XLVI, $n^{\circ}$ 4I (8-II1902), Madrid, pp. 27I-274.

FITA, Fidel; RODRÍGUEZ VILLA, Antonio, (1902): "Noticias", Boletín de la Real Academia de la Historia. Tomo XLI, Madrid, , pp. 349, 350.

6 MARTíN ESCUDERO, F., Numismática andalusí: génesis y desarrollo de una disciplina (siglos XVIII y XIX). Tesis doctoral inédita, Madrid, 2006, a quien agradecemos su colaboración. La figura 5 procede del Archivo de la Universidad de Sevilla.

7 Las medidas máximas de la inscripción, tomadas in situ en el Museo Arqueológico Nacional, son $85,5 \times 61 \times 17$ cm.; las correspondientes al campo epigráfico son 50 × 35,5 cm. 
HERNANDEZ, Félix, (1940): "Bury al-Hamma-Burgalimar, Castillo de Baños de la Encina", Al-Andalus 5, pp. 4l345.

LABARTA, Ana, (1990), "Las lápidas árabes de la Provincia de Jaén", en ANTONIO VALLEJO [et al.] (eds.), Homenaje a M. Ocaña, pp. 122-137, Córdoba.

LÉVI-PROVENÇAL, E, (1931): Inscripctions arabes d'Espagne, avec quarante-quatre planches en phototype. LeydeParis.

MAIER, Jorge, et alii, (2000): Comisión de Antigüedades de la Real Academia de la Historia. Andalucía. Catálogo e Índices. Madrid.

MARTÍNEZ LILLO, Sergio, (1998): Arquitectura militar andalusí en la marca media. El caso de Talabira, Talavera de la Reina.

MARTÍNEZ NÚÑEZ, Ma Antonia, (200l): "Epígrafe califal de Baños de la Encina", Tesoros de la Real Academia de la Historia, [Catálogo de exposición]. Madrid, n |6|, pp. 280-28।.
MENÉNDEZ, José L.; AZUAR, Rafael; LOZANO, Francisco José y LLOPIS, Ma Teresa, (1994): "El falso despiece de sillería en las fortificaciones de tapial de época almohade en Al-Andalus", en Actas del I Congreso de Castellología Ibérica, Aguilar de Campoo, pp. 49|-5।I.

REVILLA VIELVA, Ramón, (1924): La colección de epígrafes y epitafios árabes del Museo Arqueológico Nacional, Sep. de la Revista de Archivos, Bibliotecas y Museos, Madrid, 1924.

REVILLA VIELVA, Ramón, (1932): Catálogo de las antigüedades que se conservan en el patio árabe del Museo Arqueológico Nacional, Madrid, 1932

RIBERA, Julián, (1909): "Lápidas arábigas e históricas de los castillos de Tarifa y Baños de la Encina", Boletín de la Real Academia de la Historia. Madrid. Tomo LV, pp. 427433.

ZOZAYA, Juan, (1995): "Ficha 19. Inscripción", en El Zoco. Vida económica y artes tradicionales en Al-Andalus y Marruecos, Jaén, p. 98. 


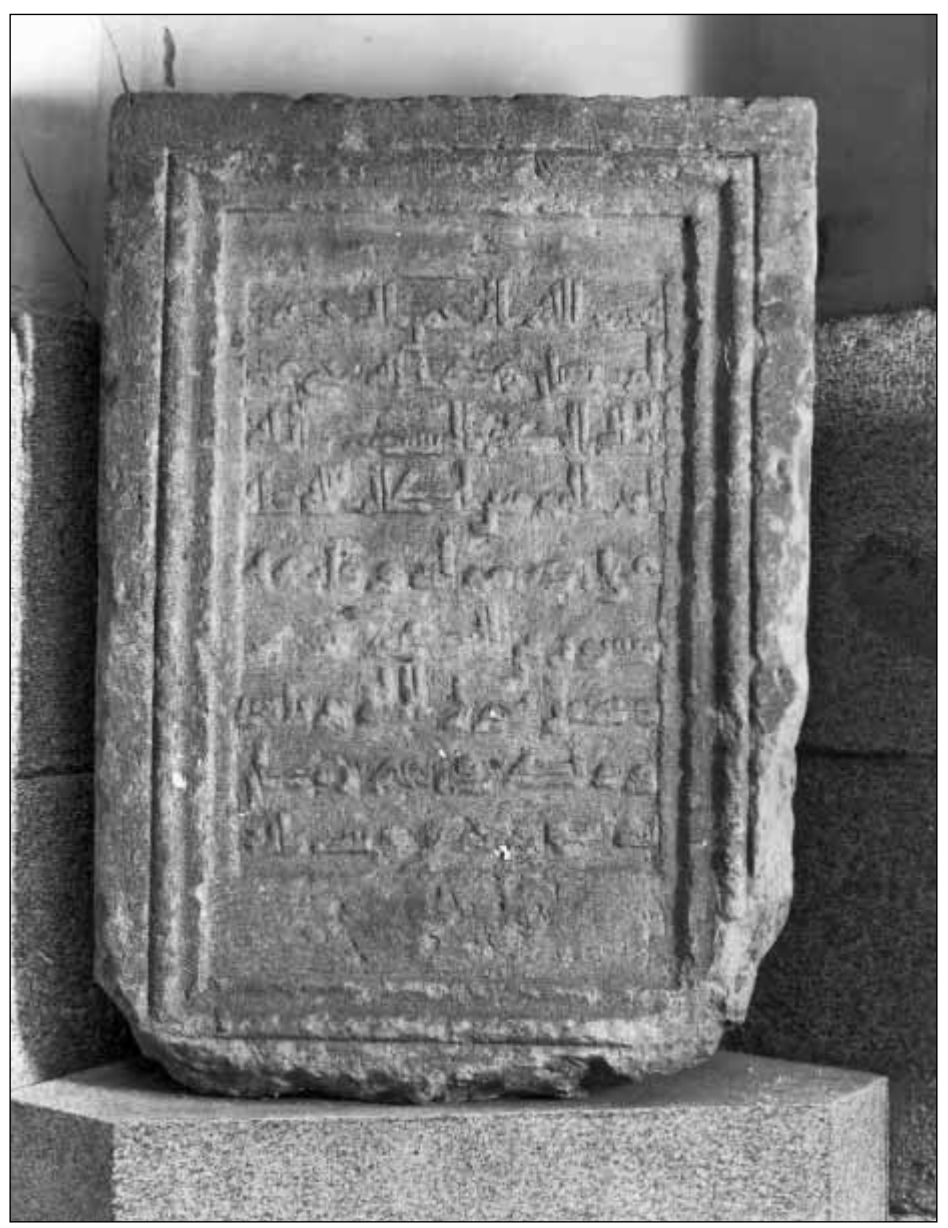

Lám. I. Fotografía de la inscripción

del castillo de Baños de la Encina

(RAH 1907/IOI; MAN 12-L).

Lám. 2. Fotografía de la inscripción hallada en Baños de la Encina en 1902, donada a la Real Academia de la Historia, y depositada en el MAN (RAH 1907/97; MAN 10-J).

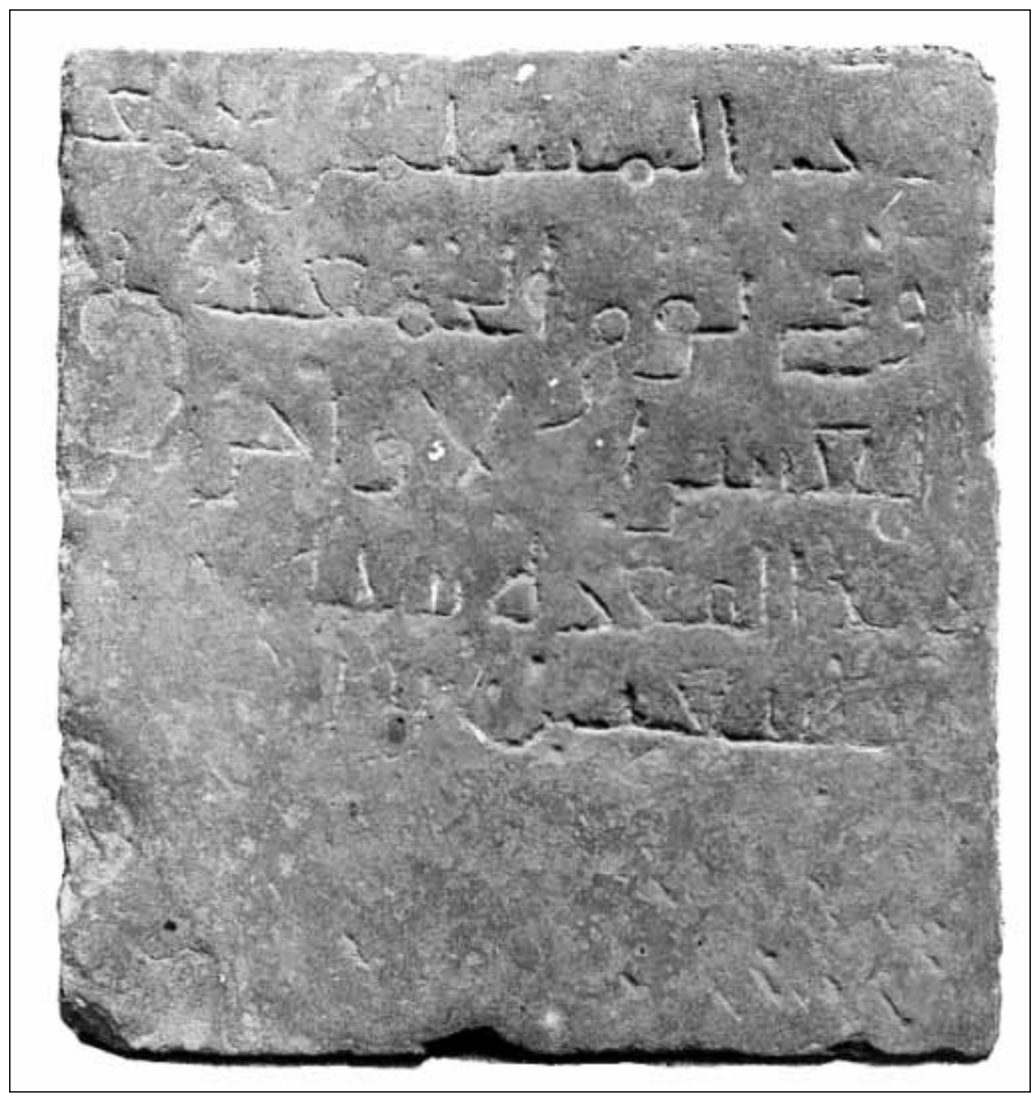




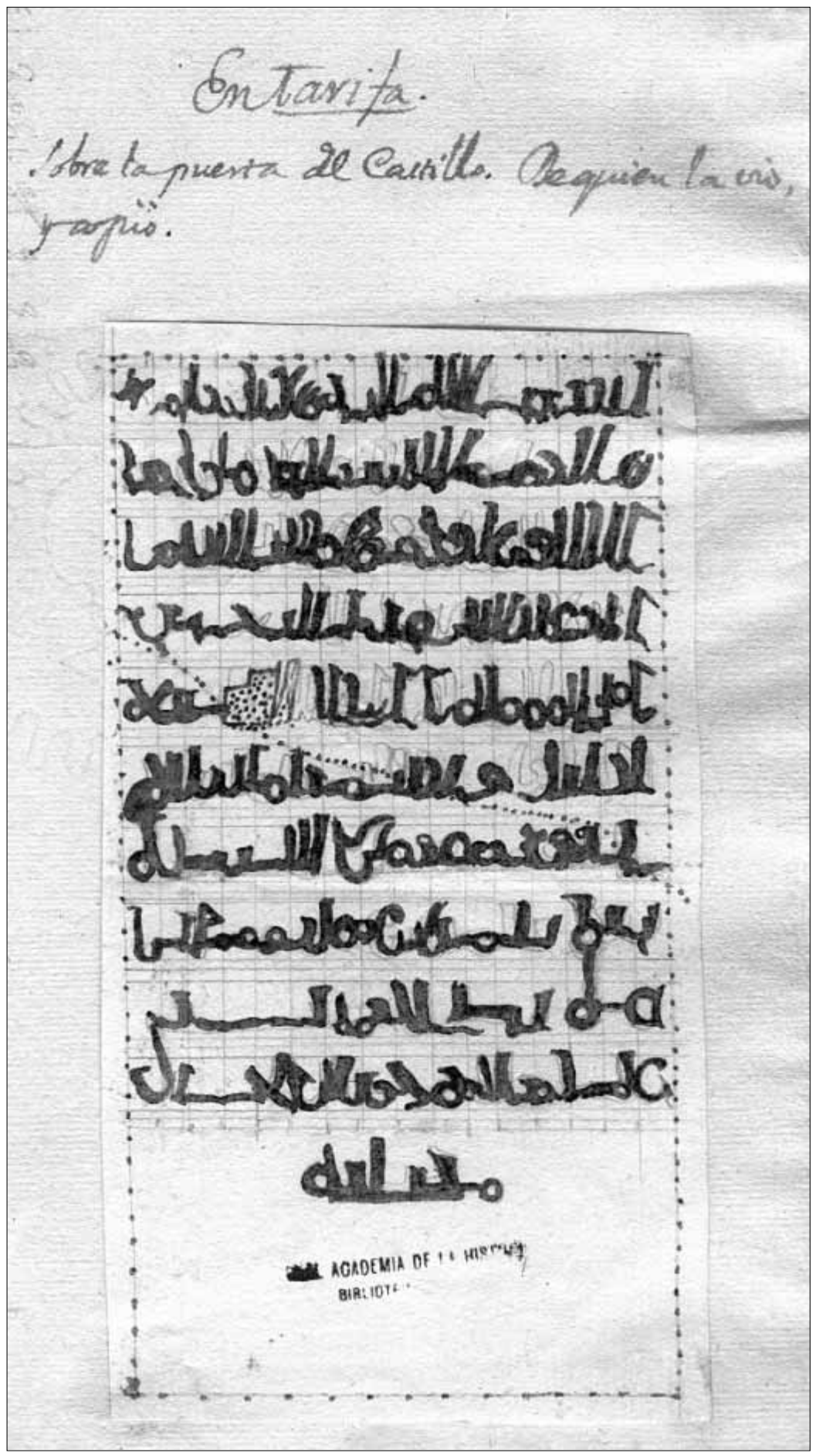

Lám. 3. Ficha de la inscripción del castillo de Tarifa, de L. J. Velázquez (RAH 9/4 / 28.37.6). 


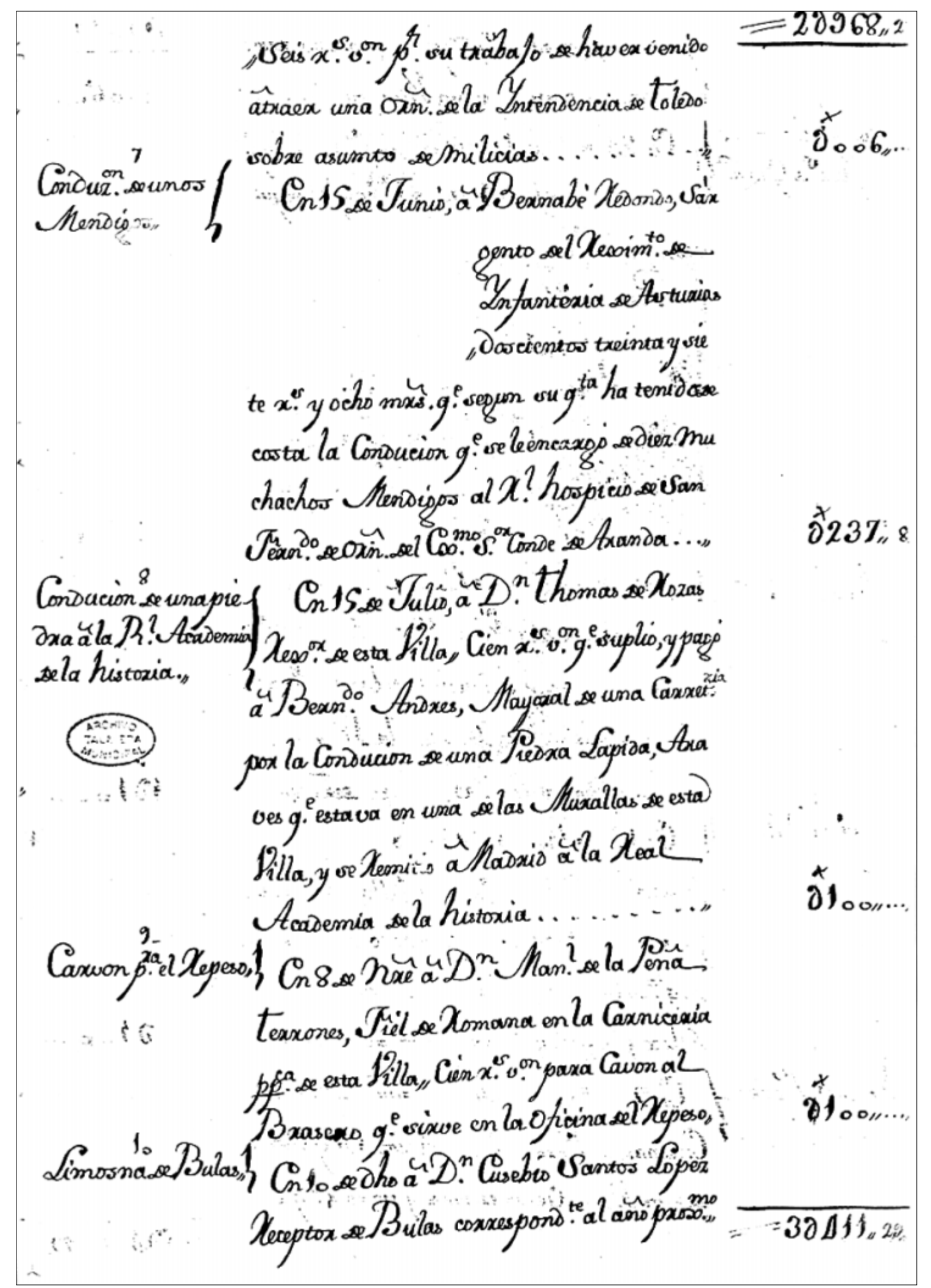

Lám. 4. Página del libro Valor de las Rentas de propios y arbitrios, de Talavera de la Reina, de 1768, en el que se menciona la inscripción y su traslado a la Real Academia de la Historia. 


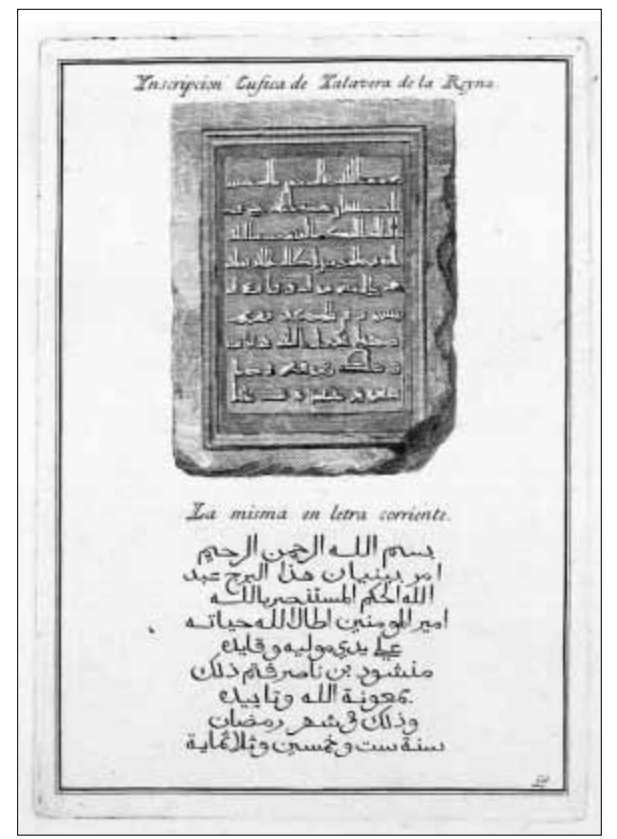

Fig. 5. Reproducción de la lámina 48 de las encargadas por la Academia al grabador Jerónimo Gil (Arch. Universidad de Sevilla).

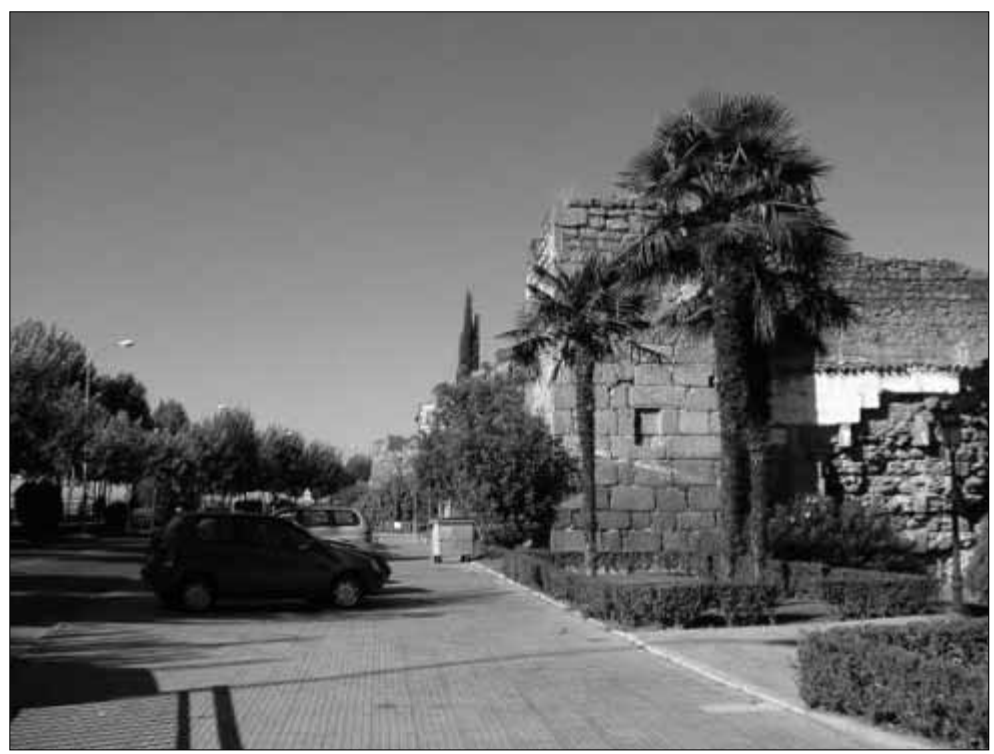

Lám. 5. Torre de Talavera de la Reina donde es visible el rebaje de los sillares destinado posiblemente a contener la inscripción conmemorativa de la obra. 